\title{
¿NÓDULO DE VIRCHOW O DE TROISIER?: VIEJA DISPUTA ENTRE LA LITERATURA MÉDICA DE HABLA INGLESA Y HABLA FRANCESA*
}

\author{
Drs. Claudio Cortés A. ${ }^{1}$, José A. de Grazia K. ${ }^{1}$ \\ 1 Centro de Imagenología, Hospital Clínico de la Universidad de Chile. \\ Santiago, Chile.
}

\section{Virchow or Troisier node? Old dispute between english and french medical literature}

Mujer de 69 años que consulta por dispepsia, baja de peso y presencia de un nódulo no doloroso en la fosa supraclavicular izquierda de varios meses de evolución. El examen físico evidencia un nódulo de consistencia pétrea, de $3 \mathrm{~cm}$ de diámetro, en la fosa supraclavicular izquierda (Figura 1). Se realiza una tomografía computada de abdomen y pelvis que demuestra en el topograma un engrosamiento parietal estenosante del antro gástrico, hallazgo que es confirmado en los cortes axiales que evidencian una masa antral estenosante de aspecto neoplásico (Figura 2). La paciente es sometida a cirugía y la biopsia de la lesión demuestra un adenocarcinoma gástrico infiltrante (Figura 3).

El nódulo de Virchow, también llamado en la literatura francesa nódulo de Troisier, es una adenopatía supraclavicular, habitualmente izquierda, correspondiente a metástasis ${ }^{1,2}$. Los tumores que dan metástasis a este sitio son carcinomas primarios de órganos torácicos o abdominales, con mayor frecuencia cáncer gástrico ${ }^{1,2}$. Debido a su carácter invariablemente maligno, ha recibido también el nombre de "nódulo centinela"2.

No hay duda de la primacía de Rudolf Ludwig Karl Virchow, el médico más prominente en la Alemania del Siglo XIX, en la descripción de este nódulo, quien ya en 1848 publica la diseminación de tumores abdominales

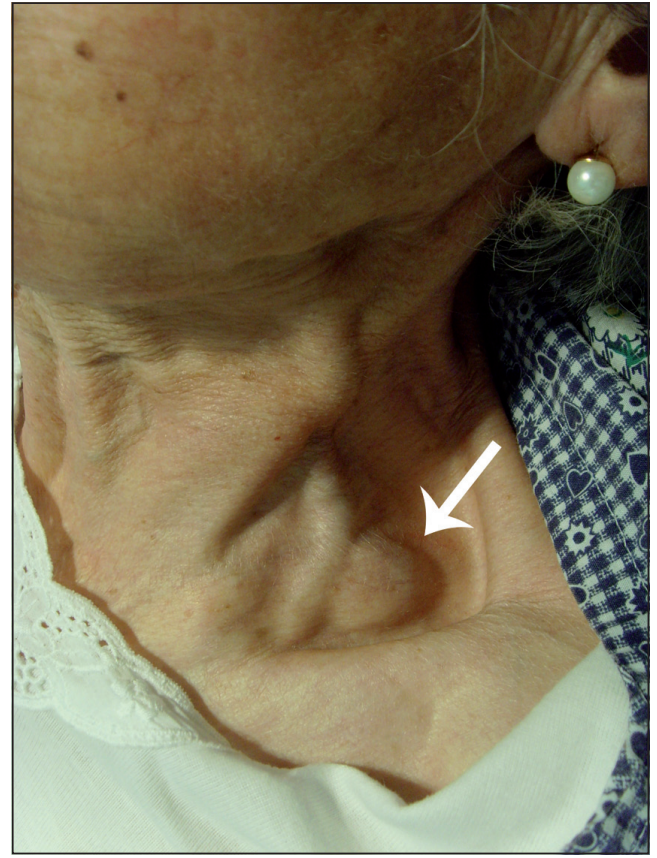

Figura 1. Adenopatía supraclavicular izquierda de $3 \mathrm{~cm}$ de diámetro (flecha).

*Recibido el 29 de septiembre de 2013 y aceptado para publicación el 27 de octubre de 2013.

Correspondencia: Dr. Claudio Cortés A.

Av. Santos Dumont 999, Santiago, Chile.

claudiocort@gmail.com 


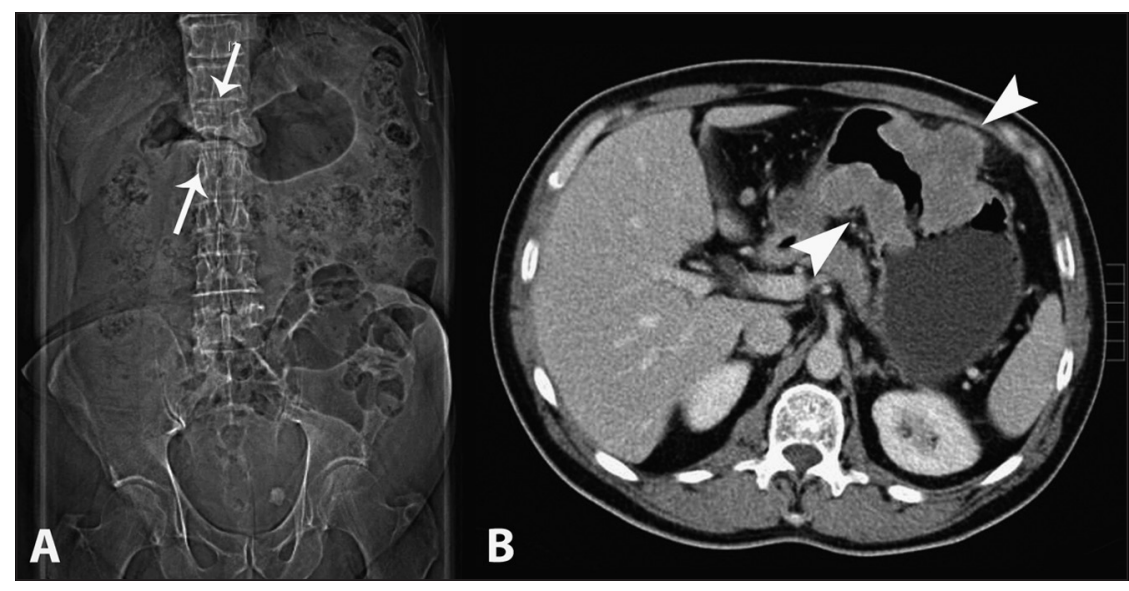

Figura 2. Tomografía computada de abdomen y pelvis, que demuestra en el topograma un engrosamiento parietal estenosante del antro gástrico (imagen $\mathrm{A}$, flechas). Un corte axial en fase porto-venosa confirma la presencia de una masa gástrica antral estenosante, con aumento de atenuación del tejido adiposo adyacente, altamente sugerente de neoplasia gástrica (imagen B, cabezas de flecha).

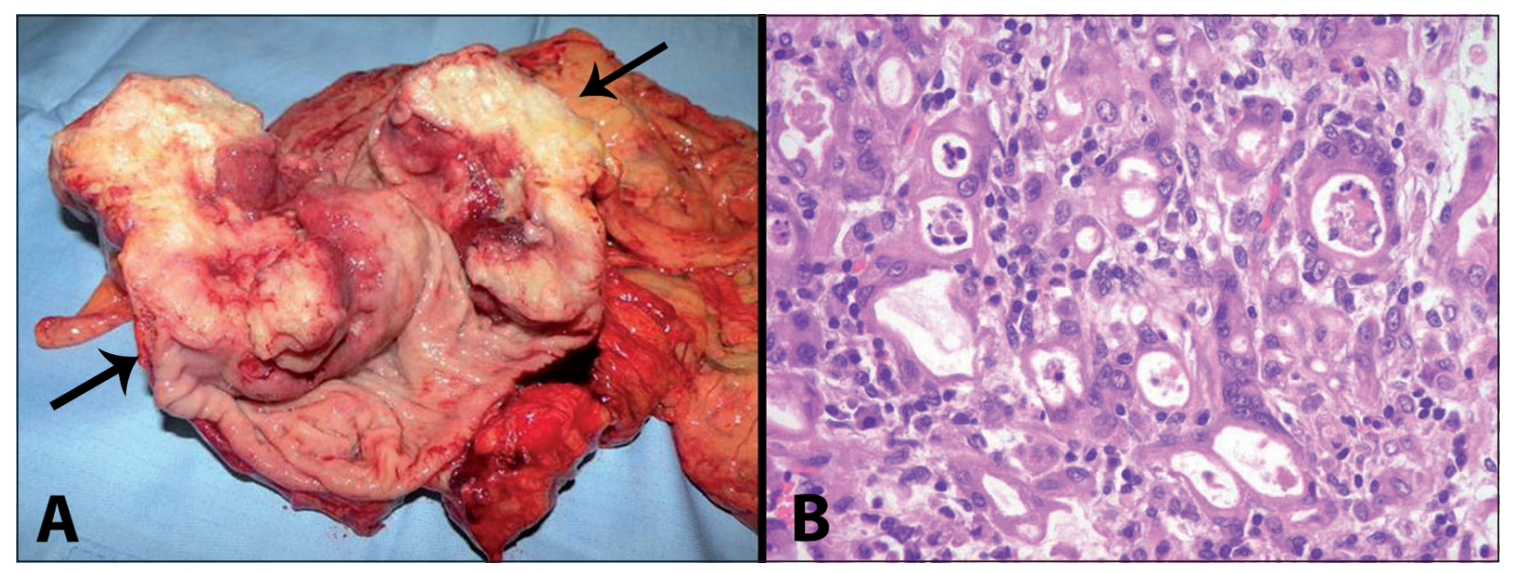

Figura 3. Pieza quirúrgica resecada, con presencia de un tumor gástrico infiltrativo (imagen A, flechas). El examen histológico de la lesión, con tinción hematoxilina-eosina y aumento $100 \mathrm{x}$, confirma la presencia de un adenocarcinoma infiltrante (imagen B).

hacia la región supraclavicular³. Cuatro décadas más tarde, Charles-Emile Troisier, clínico y anátomopatólogo francés, describe nuevamente esta entidad y agrega más casos a los ya conocidos ${ }^{4}$. Hasta nuestros días se ha mantenido la dualidad en su denominación, siendo llamado nódulo de Virchow en la mayoría del mundo y nódulo de Troisier en Francia y otras regiones de habla francesa ${ }^{1}$. Sugerimos denominarlo nódulo de Virchow-Troisier a modo de uniformar criterios y rendir homenaje a dos tan importantes médicos del siglo XIX.

\section{Referencias}

1. Morgenstern L. The Virchow-Troisier node: a historical note. Am J Surg. 1979;138:703.

2. Scully C, Langdon J, Evans J. Marathon of eponyms: 22 Virchow node. Oral Dis. 2012;18:107-8.

3. Virchow R. "Zur Diagnose der Krebse in Unterleibe". Med Reform. 1848;45:248.

4. Troisier CE. "L'adénopathie sus-claviculaire dans les cancers de l'abdomen". Arch Gen de Med. 1889; 1:129138 and 297-309. 